\title{
Antibody Responses to Antigens of Streptococcus mutans in Monkeys (Macaca fascicularis) Immunized against Dental Caries
}

\author{
By R. R. B. RUSSELL, ${ }^{*}$ SUSAN L. PEACH, $†$ G. COLMAN $\ddagger$ AND \\ B. COHEN \\ Dental Research Unit, Royal College of Surgeons of England, Downe, Orpington, \\ Kent BR6 7JJ, U.K.
}

(Received 23 August 1982)

\begin{abstract}
Immunization of rabbits or monkeys with walls prepared from Streptococcus mutans by a procedure including extraction with SDS at room-temperature induced antibodies to three antigens (A, B and C) detectable by crossed immunoelectrophoresis. Antigens A and B have previously been characterized as proteins of molecular weight 29000 and 190000 , respectively. Antigen $\mathrm{C}$ was characterized as having a molecular weight of 70000 and was purified by immunosorbent affinity chromatography and hydrophobic interaction chromatography. Another wall protein, antigen D, of molecular weight 13000 , was extracted from walls with Triton X-100. Immunization of monkeys with walls prepared from cultures of $S$. mutans grown at a high $\left(D=0.5 \mathrm{~h}^{-1}\right)$ or low $\left(D=0.05 \mathrm{~h}^{-1}\right)$ dilution rate in a chemostat showed that only the latter induced protection against dental caries. There was a positive correlation between levels of antibody to antigens $\mathrm{A}$ and $\mathrm{C}$ and induction of protection and a negative correlation between protection and the level of antibody to antigen $B$. No antibody to antigen D was detected in protected monkeys and an experiment in which monkeys were immunized with pure antigen $D$ confirmed that it does not induce protection.
\end{abstract}

\section{INTRODUCTION}

Streptococcus mutans is believed to be of prime significance in dental caries and reports from a number of laboratories have described the successful immunization of experimental animals against the disease with vaccines based on $S$. mutans (reviewed by McGhee \& Michalek, 1981). Experiments involving monkeys have indicated that a protein component of the wall of $S$. mutans is essential for protection (Colman \& Cohen, 1979; Russell et al., 1979) and we have previously described wall-associated protein antigens A and B of $S$. mutans serotype $c$ and their use as purified vaccines (Russell, 1979a, b; Russell et al., 1982). Antigens A and B were identified as proteins which remain associated with walls even after extraction with the detergent SDS at $100^{\circ} \mathrm{C}$. Walls prepared by more gentle methods can also confer protection against caries (Bowen et al., 1975; Cohen et al., 1979) and the possibility existed that such wall preparations contained potentially protective antigens in addition to $\mathrm{A}$ and $\mathrm{B}$. Cohen et al. (1979) also described an experiment in which monkeys were immunized with walls prepared from $S$. mutans grown at different rates in a chemostat and presented preliminary data showing that a slow growth rate resulted in walls conferring most protection. Those preliminary data are extended in the present paper which describes the antigenic analysis of the protein component of $S$. mutans walls, the characterization and purification of two new antigens (C and D) and an analysis of immune response and caries development in immunized monkeys.

$\dagger$ Present address: London Chest Hospital, Bonner Road, London E2, U.K.

$\ddagger$ Present address: Central Public Health Laboratory, Division of Hospital Infection, Colindale Avenue, London NW9 5HT, U.K. 
Some of the results were presented at the VIIIth International Symposium on Streptococci and Streptococcal Diseases in June 1981 (Peach \& Russell, 1982) and at the 94th Ordinary Meeting of the Society for General Microbiology in Cambridge, April 1982.

\section{METHODS}

Organisms and growth conditions. The following strains, representing Streptococcus mutans serotypes $a$ to $h$, were used: AHT and OMZ-61 (a); FA1 and OMZ-52 (b); Ingbritt, NCTC 10449, FW293, GS-5, OMZ-70, C67-1, 3209 $(c) ; \mathrm{B} 13(d) ; \mathrm{P} 4(e) ; 151(f) ; \mathrm{K} 1(g) ; \mathrm{MFe} 28(h)$.

For the preparation of large volumes of culture, Tryptone-yeast extract broth (Tryptone $10 \mathrm{~g}$; yeast extract, $3 \mathrm{~g}$; $\mathrm{NaCl}, 2 \mathrm{~g} ; \mathrm{K}_{2} \mathrm{HPO}_{4}, 2 \mathrm{~g} ; \mathrm{NaHCO}_{3}, 1 \mathrm{~g}$; glucose, $5 \mathrm{~g}$; distilled water, 1 1) was used with the pH maintained at $6 \cdot 5$ by the automatic addition of $\mathrm{KOH}$. Extracellular proteins were also prepared from the supernatant of cultures grown in a semi-defined medium consisting of Casamino acids with added salts, vitamins and bases (Russell, $1979 c)$.

Chemostat growth of $S$. mutans Ingbritt used to prepare vaccines for experiment 19 (see below) was kindly undertaken by $\mathbf{M}$. Hughes of the Wellcome Research Laboratories using the medium and conditions described by Ellwood et al. (1974). In later experiments $S$. mutans was grown in a 11 fermentation vessel (Series $500, \mathrm{~L}$. H. Engineering, Stoke Poges, Bucks.) at $37^{\circ} \mathrm{C}$ in the medium described by Wenham et al. (1979) with the addition of cysteine hydrochloride $\left(\mathrm{g} \mathrm{l}^{-1}\right)$ and glucose $\left(6 \mathrm{~g} \mathrm{l}^{-1}\right)$. This concentration of glucose was growth-limiting.

Preparation of SDS-washed walls. Streptococcus mutans grown as described above was heated at $60^{\circ} \mathrm{C}$ for $30 \mathrm{~min}$ to inactivate autolytic enzymes and washed twice by centrifugation in $0.15 \mathrm{M}-\mathrm{NaCl}$. The bacteria were then broken by shaking with glass beads (Ballotini no. 12) in a Mickle tissue disintegrator for 20 min or in a Braun cell homogenizer for $3 \mathrm{~min}$. Broken bacteria were separated from the beads with a sintered glass filter funnel and washed twice by centrifugation with distilled water, twice with $1 \mathrm{M}-\mathrm{NaCl}$ and then resuspended in $1 \%$ (w/v) SDS at room temperature with the aid of a glass/Teflon tissue grinder. Intact bacteria were removed by centrifugation at $3000 \mathrm{~g}$ for $20 \mathrm{~min}$. The walls were sedimented by centrifugation at $11000 \mathrm{~g}$ for $20 \mathrm{~min}$. The walls were again resuspended in SDS and the differential centrifugation was repeated. Finally walls were washed three times in distilled water and freeze-dried.

Mutanolysin digestion of walls. Mutanolysin M-1 enzyme was generously provided by M. Yokogawa (Yokogawa et al., 1975). SDS-washed walls were suspended at a concentration of $20 \mathrm{mg} \mathrm{ml}^{-1}$ with $200 \mu \mathrm{g} \mathrm{M}^{-1} \mathrm{ml}^{-1}$ in $0.01 \mathrm{M}^{-}$ Tris/maleate/ $\mathrm{NaOH}$ buffer $\left(\mathrm{pH} 7 \cdot 0\right.$ ) and mixed overnight at $37^{\circ} \mathrm{C}$. Insoluble material was removed by centrifugation and discarded.

Preparation of antisera in rabbits. Injection schedules consisted of two or more intramuscular injections of $1 \mathrm{mg}$ walls or 50 to $100 \mu \mathrm{g}$ pure antigen in $0.9 \mathrm{ml}$ phosphate-buffered saline containing $0.1 \mathrm{ml}$ aluminium hydroxide (Serva Alu Gel S, Uniscience, Cambridge) at 3-weekly intervals. Rabbits were bled 1 week after a booster and the immunoglobulin fractions of antisera were prepared by either the method of Closs et al. (1975) or Steinbuch \& Audran (1969).

Electrophoretic techniques. Methods for rocket and crossed immunoelectrophoresis, SDS-PAGE and isoelectric focusing have been described previously (Russell, 1979b). Crossed immunoelectrofocusing was also performed in agarose by the method of Rosen et al. (1979). For two-dimensional electrophoresis the procedure of O'Farrell (1975) was followed, except that agarose was used for the stacking gel in the second dimension (Aasted, 1980).

Proteins were transferred electrophoretically from acrylamide gels to nitrocellulose and probed with antiserum ('Western blotting') by published procedures (Towbin et al., 1979; Burnette, 1981). Antigens to which antibody had bound were located with staphylococcal Protein A (Sigma) radioiodinated by the method of Erlich et al. (1978) followed by autoradiography or by peroxidase-conjugated swine antiserum to rabbit immunoglobulins (Dako, Mercia Brocades, Weybridge) and subsequent incubation with 3-amino-9-ethyl carbazole (Karcher et al., 1981).

Experiments with radio-labelled antigens. Antigen preparations were labelled with ${ }^{125} \mathrm{I}$ by use of $1,3,4,6-$ tetrachloro-3 $\alpha, 6 \alpha$-diphenyl glycouril-coated beads (Iodo-beads, Pierce \& Warriner Ltd, Chester). Antigen preparation $(100 \mu \mathrm{l}$ containing approximately $100 \mu \mathrm{g}$ total protein) was placed in a tube with a single Iodo-bead and $50 \mu \mathrm{Ci} \mathrm{Na}{ }^{125} \mathrm{I}(1.85 \mathrm{MBq}$; Amersham). After $15 \mathrm{~min}$ at room temperature the reaction was terminated by removing the bead and adding $10 \mu \mathrm{l} 2.5 \mathrm{M}-\mathrm{NaI}$ as carrier.

Identification of antigens in individual immunoprecipitates was performed essentially as described by Norrild et al. (1977): $20 \mu \mathrm{l}$ of an ${ }^{125}$ I-labelled crude antigen pool was subjected to crossed immunoelectrophoresis on a $5 \times 5 \mathrm{~cm}$ slide with antiserum raised against SDS-washed walls. The slide was washed, dried and stained in the same manner as for non-radioactive slides then placed in water for $5 \mathrm{~min}$ to soften the agarose. Non-overlapping regions of each stained precipitin peak were excised with a scalpel blade and transferred to sample buffer containing SDS for solubilization prior to PAGE. Gel slabs were dried on Whatman $3 \mathrm{MM}$ filter paper using a Bio-Rad Model 224 drier (Bio-Rad) and autoradiographs were prepared by exposing dried gels to Kodak X-Omat AR film with Du Pont Lightning Plus intensifying screens at $-20^{\circ} \mathrm{C}$ (Swanstrom \& Shank, 1978). 
Immunoprecipitation experiments in which radiolabelled antigen/antibody complexes were collected on Protein A-bearing staphylococci (Pansorbin, Calbiochem) for analysis by SDS-PAGE used methods described by Kessler (1981).

Purification of antigen $C$. Culture filtrate of $S$. mutans strain Ingbritt was brought to $65 \%$ saturation at $4{ }^{\circ} \mathrm{C}$ with ammonium sulphate. The precipitate which formed overnight was collected by centrifugation and redissolved in $0.05 \mathrm{M}$-Tris/ $\mathrm{HCl}$ buffer $(\mathrm{pH} 7.5)$ at a concentration of approximately $1 \mathrm{mg} \mathrm{ml}^{-1}$ before being passed through a chromatography column containing $9 \mathrm{ml}$ Sepharose CL-6B (Pharmacia) and $500 \mathrm{mg}$ mutan. Mutan is the waterinsoluble glucan produced from sucrose by $S$. mutans and was prepared as described by Russell (1979d). This affinity column removed the bulk of the glucan-binding proteins which would otherwise be retained nonspecifically by subsequent immunosorbent columns (Russell, 1981). Two procedures for purification of antigen C have been used. In the first, briefly described elsewhere (Peach \& Russell, 1982), the antigen preparation after passage through the mutan/Sepharose column was passed through a series of immunosorbent columns prepared by coupling the IgG fraction of serum from immune rabbits to cyanogen bromide-activated Sepharose (Pharmacia). The columns contained (1) monospecific antibody to antigen A, (2) monospecific antibody to antigen B, (3) antibody to SDS-washed walls (i.e. antibody to antigens A, B and C). Preparation and use of immunosorbent columns was as described by Russell (1981). Antigens A and B were retained by the first two immunosorbent columns and hence only antigen $\mathrm{C}$ was bound to the final column and could be eluted from it by $3 \mathrm{M}$-sodium thiocyanate in $0.05 \mathrm{M}$-Tris/ $\mathrm{HCl} \mathrm{pH} \mathrm{7.5}$. Fractions containing antigen were pooled, after detection by rocket immunoelectrophoresis into antiserum to SDS-washed walls.

In the second procedure, eluate from the mutan/Sepharose column was passed through the immunosorbent column containing antibody to SDS-washed walls. After extensive washing of the column with Tris buffer, antigens $\mathrm{A}, \mathrm{B}$ and $\mathrm{C}$ were eluted with thiocyanate as above. The fractions of eluate which contained antigen were dialysed first against $0.05 \mathrm{M}$-Tris/ $\mathrm{HCl} \mathrm{pH} 7.5$ and then against the same buffer containing $1 \mathrm{M}$-ammonium sulphate. The antigen sample was then applied to a chromatography column containing Phenyl-Sepharose CL-4B (Pharmacia). Proteins retained by the column were eluted by a gradient of decreasing ammonium sulphate concentration and concurrently increasing ethylene glycol concentration [final concentration 0 and $50 \%(\mathrm{v} / \mathrm{v})$, respectively]. Antigen $\mathrm{C}$ was eluted between 0.6 and 0.7 M-ammonium sulphate $/ 15$ to $20 \%(\mathrm{v} / \mathrm{v})$ ethylene glycol in advance of antigens $\mathrm{A}, \mathrm{B}$ and any residual glucan-binding proteins.

Purification of antigen $D$. Lyophilized $S$. mutans walls (approximately $20 \mathrm{mg} \mathrm{m}^{-1}$ ) prepared as described above were extracted with $1 \%$ Triton $\mathrm{X}-100$ in $0.05 \mathrm{M}-\mathrm{Tris} / \mathrm{HCl} \mathrm{pH} 7.5$ on a stirrer overnight at room temperature. Insoluble material was removed by centrifugation and the extract was applied to a column containing DEAESephadex A25 (Pharmacia) equilibrated with $0.05 \mathrm{M}$-Tris/ $\mathrm{HCl} \mathrm{pH} \mathrm{7.5.} \mathrm{After} \mathrm{extensive} \mathrm{washing} \mathrm{to} \mathrm{remove} \mathrm{all}$ detergent, the column was eluted with a gradient of 0 to $0.3 \mathrm{M} \mathrm{NaCl}$ in $0.05 \mathrm{M}$-Tris/ $\mathrm{HCl} \mathrm{pH} 7.5$ and fractions were collected and examined by SDS-PAGE for their content of antigen D. Fractions containing antigen were pooled, concentrated by lyophilization and applied to a column of Bio-Gel P-150 (Bio-Rad). Fractions containing antigen eluted from the column were again detected by SDS-gel electrophoresis and pooled. Throughout the purification the presence of other wall antigens was monitored by SDS-gel electrophoresis and rocket immunoelectrophoresis into antiserum raised against walls.

Antigen contents of other serotypes. The collection of strains of $S$. mutans was examined for the presence of different antigens by testing for reaction with rabbit antisera specific for each antigen (A, B, C and D) in the following tests: (1) immunodiffusion of concentrated culture supernatants or mutanolysin-digested bacteria (Russell, 1980); (2) agglutination of cultures either on slides or in U-well microtitration trays containing a standardized bacterial suspension and serially-diluted antiserum; (3) a procedure in which microtitration tray wells were coated with whole bacteria and the extent to which antiserum bound was assessed by ELISA (Russell \& Beighton, 1982).

Monkey immunization experiments. Three separate experiments involving Macaca fascicularis monkeys are described. Details of the earliest experiment including the source of the animals, their diets and dental caries experience have been described as experiment $\mathrm{C}$ of Bowen et al. (1975) and Cohen et al. (1979).

Experiment 19 was briefly described by Cohen et al. (1979) and further details of diet composition and methods for bacteriological examination of dental plaque were presented by Beighton \& Hayday (1982). At the start of the experiment groups of monkeys immunized with whole bacteria were included (Cohen et al., 1979) but these groups had to be discarded because of several incidental deaths among the animals. The groups described in the present report were: (1) a control group of five monkeys (three males and two females), mean age 9.4 months, mean weight $1.34 \mathrm{~kg}$ at the start of the experiment; (2) four monkeys (three males and one female, mean age 9.75 months, mean weight $1.42 \mathrm{~kg}$ ) which were immunized with walls prepared from $S$. mutans grown in a chemostat at $D=0.5 \mathrm{~h}^{-1}$; (3) three monkeys (two males and one female, mean age 11.3 months, mean weight $1.28 \mathrm{~kg}$ ) which were immunized with walls from $S$. mutans grown in a chemostat at $D=0.05 \mathrm{~h}^{-1}$. The immunization schedule used in experiment 19 was arranged to resemble that used earlier in experiment $\mathrm{C}$ of Bowen et al. (1975), i.e. multiple injections totalling $0.5 \mathrm{mg}$ walls in sterile saline were made into the mucosal surfaces of the mouths. Nine 
injections were administered at 2-weekly intervals prior to exposure to the caries-promoting sucrose-rich (CHS) diet. Booster injections were administered by the same route $7,11,14,23$ and 38 months after the start of the experiment.

Experiment 23 differed from earlier experiments in that the animals were housed in two large communal groups instead of singly or in pairs. The animals in this experiment have also been the subject of a bacteriological study (Group 2 described in Beighton \& Hayday, 1982). When immunization was commenced, the animals were assigned as controls (four males, two females, mean age 9.8 months, mean weight $1.2 \mathrm{~kg}$ ), a group immunized with pure antigen $D$ (four males, two females, 9.0 months, $1.15 \mathrm{~kg}$ ) and a group immunized with walls which had been digested with mutanolysin (three males, one female, 8.0 months, $1.14 \mathrm{~kg}$ ). For immunization with antigen $\mathrm{D}$ or wall-digest, monkeys were injected with $50-100 \mu \mathrm{g}$ protein in sterile solution with $10 \%(\mathrm{w} / \mathrm{v})$ aluminium hydroxide adjuvant at two subcutaneous sites in the lower limbs. Injections were given at the start of the experiment and 1, 3 and 12 months thereafter.

Methods of blood sampling and procedures for assay of antibody levels by ELISA were as described by Russell \& Colman (1981).

\section{RESULTS}

Rabbits immunized with $S$. mutans Ingbritt which had been extracted with SDS at $100{ }^{\circ} \mathrm{C}$ produced antibodies to only two protein antigens, A and B (Russell, 1979a,b). In contrast walls washed in SDS at room temperature as described in Methods induced antibody to three antigens which could be detected by crossed immunoelectrophoresis (Fig. 1). The same three antigens were present in mutanolysin-digests of walls and in culture supernatant preparations and so must exist in a wall-associated form which resists removal with SDS, as well as being released into the growth medium. Of a total of eight rabbits immunized with walls, all developed antibody to the same three antigens, though the relative levels of antibody to each antigen depended on the source of the walls used for immunization (see below).

The new antigen $\mathrm{C}$ was destroyed by pronase, indicating that it was a protein. Its physical characteristics were determined by crossed immunoelectrophoresis in which the first dimensional separation was by SDS-PAGE or by isoelectric focusing in polyacrylamide or agarose. The results obtained indicated that antigen $\mathrm{C}$ had a molecular weight of 70000 and an isoelectric point of $4 \cdot 45$.

The size of antigen $\mathrm{C}$ was also determined in another experiment in which an ${ }^{125} \mathrm{I}$-labelled antigen preparation was subjected to crossed immunoelectrophoresis against antiserum to walls. The radioactive immunoprecipitates were solubilized in SDS and the antigens in each precipitate identified by slab gel electrophoresis followed by autoradiography. Non-radioactive molecular weight standards were used on the same slab to allow determination of the size of the antigens. The results (Fig. 2) confirmed the size of the antigen $C$ as 70000 . It can also be seen that the antigen B precipitin line contained not only intact B (mol. wt 190000) but many smaller fragments as well.

\section{Purification of antigen $C$}

Antigen $\mathrm{C}$ purified from the supernatant of a culture in the semi-defined medium by either of the procedures in Methods gave a single band on SDS-PAGE or isoelectric focusing in acrylamide. The size and charge of the pure molecule were the same as already determined by indirect means with unpurified material. The purity of antigen $\mathrm{C}$ was also assessed by transfer from an SDS-polyacrylamide gel slab to nitrocellulose, followed by probing with a polyvalent antiserum (i.e. the 'Western blot' technique). The antiserum used was capable of detecting at least 40 antigenic bands in crude antigen preparations, but antigen $C$ was the only one present in the purified preparation. In order to increase the sensitivity of detection of contaminants, antigen $\mathrm{C}$ was labelled with ${ }^{125} \mathrm{I}$ and subjected to gel electrophoresis and autoradiography. No other bands besides $\mathrm{C}$ were detected.

Molecular weight of antigen $\mathrm{C}$ is close to that of a major glucan-binding protein (mol. wt. 74000, Russell, 1979d), fructosyltransferase (mol. wt. 70000, Russell, $1979 e$ ) and dextranase (mol. wt approx. 80000, H. Kuramitsu and C. W. I. Douglas, personal communications). However antigen $\mathrm{C}$ could be demonstrated to be distinct from each of these by their separation 


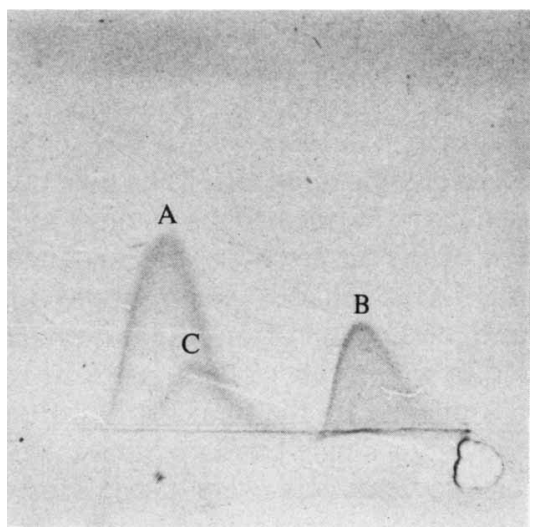

Fig. 1. Crossed immunoelectrophoresis of concentrated culture supernatant proteins $(50 \mu \mathrm{g})$ of $S$. mutans Ingbritt against rabbit antiserum to SDS-washed walls ( $100 \mu \mathrm{lin} 3 \mathrm{ml}$ agarose) on a $5 \times 5 \mathrm{~cm}$ glass slide. Electrophoresis was at $6 \mathrm{~V} \mathrm{~cm}^{-1}$ for $1.5 \mathrm{~h}$ in the first dimension (anode to left) and $1 \mathrm{~V} \mathrm{\textrm {cm } ^ { - 1 }}$ for $16 \mathrm{~h}$ in the second dimension (anode at top). The same three precipitin peaks could be detected when a mutanolysin-digested wall preparation was used as antigen.

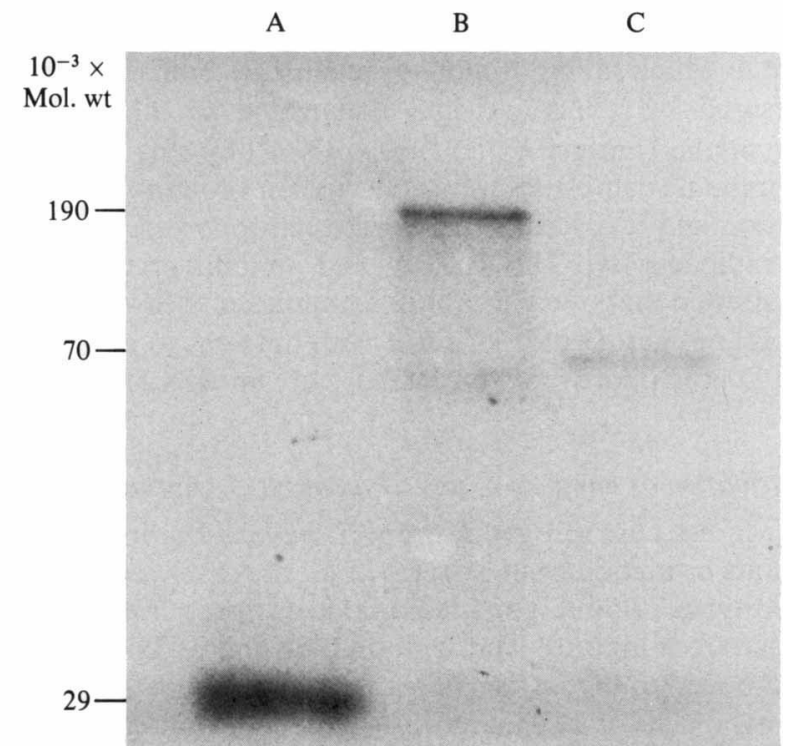

Fig. 2. Autoradiograph of SDS-polyacrylamide gel on which the samples were precipitin peaks excised from a crossed immunoelectrophoresis slide like that shown in Fig. 1, but with ${ }^{125}$ I-labelled antigen. Molecular weights of antigens A, B and C are indicated on the left hand side of the figure.

on SDS-polyacrylamide gel or isoelectric focusing; furthermore specific antiserum raised against antigen $\mathrm{C}$ did not precipitate or inhibit the function of any of the proteins having similar size.

\section{Purification of antigen D}

Antigens A, B and C are all released into culture supernatants. The possibility existed however that there were other wall protein antigens which were not released, but always remained bound to wall peptidoglycan. Samples of walls prepared by the SDS-washing procedure were therefore subjected to extraction with a wide range of different detergents, salts, 
chaotropic agents, extremes of temperature or $\mathrm{pH}$ and proteolytic or muralytic enzymes. The protein composition of extracts was examined by gel electrophoresis and it was found that besides variable but low amounts of antigens $\mathrm{A}, \mathrm{B}$ and $\mathrm{C}$ the only other band present in substantial amounts was one with a molecular weight of 13000 . This was termed antigen $D$. While antigen $\mathrm{D}$ could be effectively released from walls by a number of agents, the non-ionic detergent Triton X-100 was used in the purification procedure, so that it could be separated from extracted proteins by retention of the latter on an ion-exchange column.

Antigen D was eluted from DEAE-Sephadex A25 by approximately $0.15 \mathrm{M}-\mathrm{NaCl}$. Although SDS-PAGE suggested that antigen $D$ eluted from the ion-exchange column was pure, it was possible to demonstrate the additional presence of antigen $A$ by rocket immunoelectrophoresis. The traces of antigen A were removed by the final gel filtration step on Bio-Gel P150.

Antigen D preparations gave only a single band on SDS-PAGE when either gels of various acrylamide concentrations or gradient gels were used. However, isoelectric focusing in acrylamide (Wrigley, 1971) or two-dimensional gel electrophoresis (O'Farrell, 1975) revealed the presence of three or four closely spaced components of the same size but with values from pI $4 \cdot 5$ $4 \cdot 8$.

\section{Antigenicity of antigen $D$}

Antigen $\mathrm{D}$ forms only very faint and non-reproducible precipitin lines in agarose (presumably because of its low molecular weight). Two methods which do not rely on the formation of immunoprecipitates in gel were therefore employed to explore interactions between antigen D and antibody. In the ELISA method, the wells of plastic microtitration trays were coated with antigen D; the extent to which rabbit or monkey antibodies bound to the immobilized antigen could then be measured by using anti-IgG conjugated to alkaline phosphatase. In the immunoprecipitation method antigen $\mathrm{D}$, labelled with ${ }^{125} \mathrm{I}$ by means of Iodo-beads, was mixed with the test serum; immune complexes were collected on Protein A-containing Staphylococcus aureus by centrifugation and analysed by SDS-gel electrophoresis and autoradiography or by direct counting of radioactivity. The ELISA and immunoprecipitation procedures gave identical results and showed that of eight rabbits immunized with walls, only three had formed antibody to antigen $\mathrm{D}$; antigen $\mathrm{D}$ did not react with antisera to antigens $\mathrm{A}, \mathrm{B}$ or $\mathrm{C}$ (nor did antiserum to antigen $\mathrm{D}$ precipitate those antigens); pure antigen $\mathrm{D}$ induced a specific immune response in rabbits.

\section{Distribution of antigens $C$ and $D$ amongst $S$. mutans serotypes}

Antiserum raised against pure antigen $C$ from $S$. mutans Ingbritt (serotype $c$ ) precipitated antigens in supernatants or mutanolysin extracts of all the other serotype $c$ stock strains tested and also strains of serotypes $e$ and $f$. The precipitated antigens from all these strains formed a line of identity with that from Ingbritt. The agglutination and ELISA techniques confirmed that antibody to antigen $\mathrm{C}$ bound to the surface of bacteria of serotypes $c, e$ and $f$ and also, although more weakly, to serotype $b$ strains. This indicated that a cross-reacting antigen may exist in serotype $b$. There was no evidence for such cross-reactions from serotypes $a, d, g$ and $h$.

The poor ability of antigen $D$ to form precipitin lines precluded the use of immunodiffusion to screen for cross-reacting antigens but in both of the more sensitive agglutination and ELISA tests specific anti-D serum reacted strongly with all strains of serotypes $c, e$ and $f$, though not with representatives of other serotypes.

\section{Antibody responses in monkeys immunized with walls}

In experiment $C$ described by Bowen et al. (1975) and Cohen et al. (1979) five control monkeys were compared with four monkeys immunized with walls prepared from $S$. mutans strain Ingbritt which had been grown in a chemostat at $D 0.05 \mathrm{~h}^{-1}$. Almost total protection against caries was obtained in the immunized group. Only very limited amounts of serum from the animals in this experiment are still available but we have demonstrated by crossed immunoelectrophoresis techiques that protected animals had antibody to antigens A, B and C. There was no detectable antibody to other protein antigens. ELISA confirmed that protected 


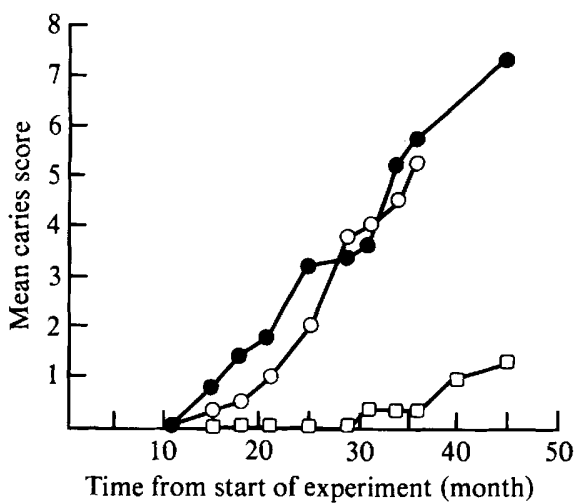

Fig. 3. Progression of dental caries in the permanent teeth of monkeys in experiment 19. Points show the mean caries score of the control group (five animals, ), the group immunized with SDS-washed walls prepared from a culture of $S$. mutans Ingbritt grown at $D=0.5 \mathrm{~h}^{-1}$ (four animals, $O$ ) and the group immunized with SDS-washed walls from a culture grown at $D=0.05 \mathrm{~h}^{-1}$ (three animals, $\square$ ).

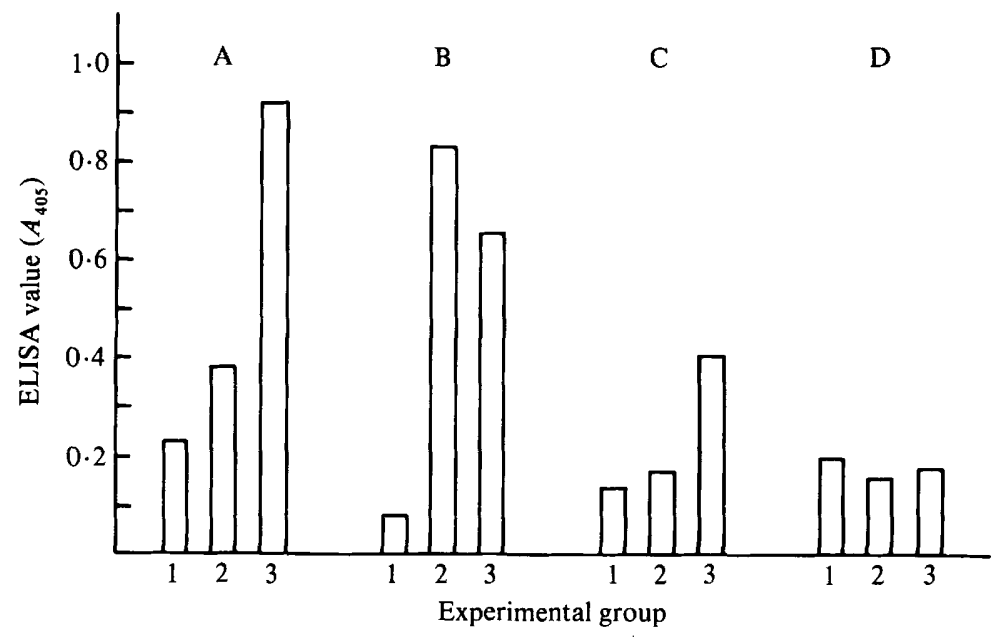

Fig. 4. Levels of serum IgG antibody in monkeys of experiment 19 to antigens A, B, C and D determined by ELISA. The bars indicate the mean values obtained from 1, controls; 2 , monkeys immunized with walls from culture grown at $D=0.5 \mathrm{~h}^{-1} ; 3$, monkeys immunized with walls from culture grown at $D=0 \cdot 05 \mathrm{~h}^{-1}$. Serum samples were from a test bleed 38.5 months after the start of the experiment and all were assayed in duplicate at a dilution of $1: 200$.

animals had significantly elevated levels of serum IgG antibody to antigens A, B and C, compared with control animals but the same method failed to demonstrate any significant difference in levels of antibody to antigen $D$.

Experiment 19 consisted of a group of control monkeys and groups immunized with walls from $S$. mutans strain Ingbritt grown at two different growth rates. Walls from the culture grown at a fast rate $\left(D=0.5 \mathrm{~h}^{-1}\right)$ failed to confer any protection. No lesions developed in the primary dentition of the animals immunized with walls from the slow-grown culture $\left(D=0.05 \mathrm{~h}^{-1}\right)$ and after 3 years on a high-sugar diet only a single lesion had developed in a permanent tooth of one animal (Fig. 3). Dental examinations of the non-protected immunized group were discontinued after 3 years, but monitoring of the remaining animals has confirmed that protection was still substantial after the monkeys had been on the high-sugar diet for a total of 45 months.

Serum antibody responses in monkeys of experiment 19 were assayed by ELISA using purified antigens A, B, C, D and also glucosyltransferase and glucan-binding protein. Immunization had no effect on levels of antibody to the last two. Data from a test bleed taken 2 weeks after the final booster injection (Fig. 4) showed that in all immunized animals there were 


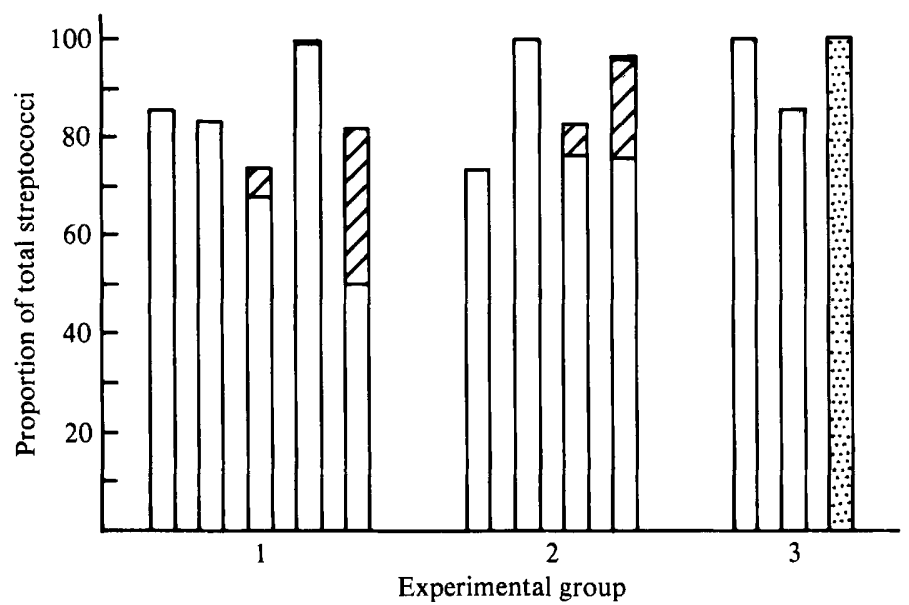

Fig. 5. The Streptococcus mutans populations in the plaque flora of monkeys in experiment 19, 25 months after introduction of the CHS diet, expressed as a percentage of the total streptococcus count. Redrawn from Table 1 of Beighton \& Hayday, 1982. Group 1, controls; group 2, monkeys immunized with walls from culture grown at $D=0.5 \mathrm{~h}^{-1}$; group 3 , monkeys immunized with walls from culture grown at $D=0.05 \mathrm{~h}^{-1} . \square$, Serotype $c ; \square$, serotype $h$; 团, serotype $e ; \square$, serotype $d / \mathrm{g}$. Each column represents a different animal.

raised levels of antibody to antigens $A$ and $B$, though no antibody to antigen $D$ could be detected and only the slow-growth rate walls had induced a significant response to antigen $\mathrm{C}$. As had been observed previously (Russell \& Beighton, 1982) control animals also develop natural antibody to $S$. mutans antigens. Marked differences were apparent in the levels of antibody to different antigens in the two immunized groups: the animals immunized with slow-growth rate walls (which were protected against caries) had higher levels of antibody to antigens $\mathrm{A}$ and $\mathrm{C}$ than did unprotected animals. The reverse was true of antibodies to antigen $B$, which were higher in the non-protected group. This difference in response between the two immunized groups was confirmed by ELISA of serum samples taken on several other occasions during the experiment, and also by titrating antibody to an end-point, a method more suited to detection low levels of antibody (Russell \& Colman, 1981).

\section{Bacteriology of group 19}

The animals in experiment 19 have been the subject of a bacteriological study which determined the levels of different $S$. mutans serotype in individual monkeys (Beighton \& Hayday, 1982). The relevant data are represented in Fig. 5.

\section{Immunization with pure antigen $D$}

Experiment 23 contained a group of six control monkeys, six immunized with antigen $\mathrm{D}$ and four immunized with a mutanolysin digest of $S$. mutans Ingbritt walls. The wall extract conferred protection against caries, albeit not as great as that observed with intact walls; after 34 months on the CHS diet the wall-immunized group had a mean of 1.25 caries lesions in their permanent teeth, with two of the animals still being caries-free. The non-immunized control group all had caries, the mean score being 3.3 while the scores of the group immunized with antigen $D$ were not statistically significantly different from those of the controls, the mean being $3 \cdot 4$. The only animals that had developed an immune response to antigen $D$ were those injected with the pure antigen.

Animals in experiment 23 were housed in communal cages, with the result that compared with animals housed individually much greater uniformity of bacterial flora was observed (Beighton \& Hayday, 1982). Serotype $e$ comprised approximately $60 \%$ of the streptococcal flora in the communes, serotype $c 20 \%$ with only low numbers of serotypes $d, g$ and $h$ being detected. 
DISCUSSION

Earlier reports from this laboratory described the characterization and purification of the protein antigens A and B (Russell, 1979 $a, b, 1980,1981$ ). These two antigens exist in forms which remain associated with walls even after being treated with SDS at $100^{\circ} \mathrm{C}$, a procedure believed to disrupt all except covalent bonds, although they are also released into culture supernatants. In the present report a milder procedure involving extraction of walls with SDS at room temperature was used but this still removed all membrane and cytoplasmic material; no further protein was removed by introducing more than two washes in SDS. This procedure allowed the recognition of the new antigen $\mathrm{C}$ but it is not clear whether antigen $\mathrm{C}$ is removed from walls by SDS at $100^{\circ} \mathrm{C}$ or whether its antigenicity is destroyed. Although antigen D was not recognized by the methods used in earlier studies, it is apparent that it remains on walls even after treatment with SDS at $100{ }^{\circ} \mathrm{C}$ because walls so treated could induce an immune response to the antigen.

Antigens $A$ and $B$ were earlier postulated to be involved in the induction of protection against caries because monkeys immunized with walls had elevated levels of antibody to both antigens (Cohen et al., 1979; Colman \& Cohen, 1979). However, Cohen et al. (1979) also noted that protected animals had developed antibody to an antigen in addition to $\mathbf{A}$ and $\mathbf{B}$ and in the present paper we have shown this to be antigen $C$. No further antigens which might be involved in protection could be detected by crossed immunoelectrophoresis of either culture supernatant or mutanolysin-digested walls against antiserum to SDS-washed walls, nor did affinity chromatography on columns constructed with antiserum to walls reveal the existence of any further antigens. Our attempts to use the sensitive 'Western Blotting' technique to determine whether immune animals have antibodies to additional antigens have been frustrated by the problems arising from degradation of antigen $B$, the fragments of which show up as multiple bands on the nitrocellulose when treated with immune serum. Similar difficulties have attended the use of immunoprecipitation of radiolabelled antigens. The available evidence however, indicates that there are no further major protein components of the $S$. mutans wall prepared by our procedure, other than A, B, C and D.

Other workers have isolated antigens, named I, II and III, from S. mutans serotype $c$ (Russell, 1979; Russell, et al., 1980). The published values for molecular weights and isoelectric points of these antigens indicate that none of them are identical to antigens $\mathrm{C}$ or $\mathrm{D}$, although antigens $\mathrm{I}$ and II can exist in a combined form (antigen I/II) which appears to correspond to our antigen $B$.

The results illustrated in Fig. 3 confirm the preliminary report by Cohen et al. (1979) that walls prepared from $S$. mutans grown at a slow-rate in a chemostat can induce effective protection against caries. Experiment 19 was designed to reproduce experiment $C$, started some 8 years earlier. In both experiments the same immunization schedule of multiple sub-mucosal injections without adjuvant was used. This regime was originally instituted in attempts to stimulate a local immune response but results already presented (Cohen et al., 1979; Russell et al., 1982) and those for experiment 23 in this paper have demonstrated that subcutaneous immunization at a site remote from the mouth is also effective. Such a route would probably be more acceptable in humans.

The monkeys in our colony harbour predominantly serotypes $c, e$ and $h$ of $S$. mutans and it has been shown that within a group of monkeys individuals may harbour different serotypes or combinations of serotypes (Beighton \& Hayday, 1982). Immunization with antigens purified from serotype $c$ should give protection against both serotypes $c$ and $e$ (and also $f$ ) because protein antigens of these serotypes are indistinguishable; serotypes carrying cross-reacting but nonidentical antigens might also be protected against. Serotypes of $S$. mutans not carrying the antigen used for immunization should be unaffected. It is obvious that spurious results could be obtained from an experiment if different groups of animals carried different $S$. mutans serotypes, particularly if the colonizing strains lacked the antigen used as vaccine, but only recently has sufficient information become available to allow adequate bacteriological characterization of the monkeys' oral flora. In experiment 19, serotype $c$ was the sole or predominant serotype of $S$. mutans in all animals except one, which carried serotype $e$. Since the wall antigens $\mathrm{A}, \mathrm{B}$ and $\mathrm{C}$ are indentical in serotypes $c$ and $e$, the difference in caries experience between the groups cannot be attributed to differences in challenge by $S$. mutans. Similarly, in 
experiment 23 for which the animals were housed in communal cages, all the animals carried serotype $e$ on their teeth, the mean level being $60 \%$ of the total cultivable streptococci, while serotype $c$ made up another $20 \%$.

Comparison of the immune responses of monkeys in experiment 19, where the group immunized with one wall preparation was protected and the other not (Fig. 3), showed that the protected animais had the highest level of antibody to antigens $A$ and $C$ (Fig. 4). In contrast, the response to antigen $B$ showed no correlation with protection. We are currently developing procedures for measuring amounts of the different antigens in wall preparations and our initial results (unpublished) have shown that $S$. mutans when growing at $D=0.05 \mathrm{~h}^{-1}$ produces substantially more antigen A than when growing at $D=0.5 \mathrm{~h}^{-1}$. Production of extracellular antigen $\mathrm{B}$ (referred to as protein $\mathrm{P} 1$ ) at different growth rates has already been measured by Hardy et al. (1982), who showed that more was produced at higher growth rates. Wall-bound antigen B (assayed by rocket immunoelectrophoresis of mutanolysin-digests) also increases with growth rate. The immune responses thus show a positive correlation with the levels of antigens $A$ and $B$ in the walls used as immunogens. Antigen $C$, however, does not appear to vary so markedly with growth rate so the variation in immunogenicity may be attributable to some other factor such as its conformation or location within the wall.

Antigen $\mathrm{D}$, in its wall-bound form, appears to be a poor immunogen as only three of eight rabbits, and none of the monkeys, immunized with walls responded to it. It is clear that antigen D could not have been responsible for the protection of the wall-immunized monkeys and the experiment where it was used as a pure vaccine (which induced a strong specific response) confirmed its inability to protect.

Although the results from experiment 19 provide indirect evidence that antigens $\mathrm{A}$ and $\mathrm{C}$ alone or in combination could be responsible for the observed reduction in caries, the only way to test the importance of each antigen conclusively is to use each as pure single-component vaccines. Antigen $C$ is currently under test; results on use of pure A and B have already been reported by Russell et al. (1982). Antigen A induced a high degree of protection (approaching $90 \%$ reduction in caries) in three separate groups of monkeys. Antigen B gave significant reduction in one experiment but this was not confirmed by a second. Apart from this lack of consistency of protection by antigen B, it should also be noted that antigen B appears to share antigenic determinants with heart tissue (Hughes et al., 1980; Russell, 1979) and the possible hazard of inducing auto-immunity due to antibody to such a cross-reactive antigen means that $B$ would be unacceptable for use as a human vaccine. Antigens $A$ and $C$ have not been shown to possess such heart cross-reactivity (M. Hughes, personal communication) and so hold considerable promise for possible use in humans.

We are grateful to David Beighton and Hazel Hayday for providing us with their data on the $S$. mutans population of the monkeys.

\section{REFERENCES}

AASTED, B. (1980). Highly purified agarose as stacking gel in sodium dodecyl sulphate/polyacrylamide-gel electrophoresis. Biochemical Journal 189, 183-184.

Beighton, D. \& HAYDAY, H. (1982). The stability of Streptococcus mutans populations in the dental plaque of monkeys (Macaca fascicularis). Journal of Applied Bacteriology 52, 191-200.

Bowen, W. H., Cohen, B., Cole, M. F. \& Colman, G. (1975). Immunisation against dental caries. British Dental Journal 139, 45-58.

BURNETTE, W. N. (1981). "Western Blotting": electrophoretic transfer of proteins from sodium dodecyl sulfate-polyacrylamide gels to unmodified nitrocellulose and radiographic detection with antibody and radioiodinated protein A. Analytical Biochemistry 112, 195-303.

Closs, O., Harboe, M. \& Wassim, A. M. (1975). Cross- reactions between Mycobacteria I. Crossed immunoelectrophoresis of souble antigens of $\mathrm{Myco}-$ bacterium lepraemurium and comparison with BCG. Scandinavian Journal of Immunology 4, (suppl. 2), 173-185.

Cohen, B., Colman, G. \& Russell, R. R. B. (1979). Immunisation against dental caries: further studies. British Dental Journal 147, 9-14.

Colman, G. \& COHEN, B. (1979). Immunisation of monkeys (Macaca fascicularis) with Streptococcus mutans. In Pathogenic Streptococci, pp. 214-215, Edited by M. T. Parker. Chertsey, Surrey: Reedbooks Ltd.

Ellwood, D. C., Hunter, J. R. \& Longyear, V. M. C. (1974). Growth of Streptococcus mutans in a chemostat. Archives of Oral Biology 19, 659-664.

Erlich, H. A., Cohen, S. N. \& McDevitT, H. O. 
(1978). A sensitive radioimmunoassay for detecting products translated from cloned DNA fragments. Cell 13, 681-689.

Hardy, L., Jacques, N. A., Forester, H., Campbell, L. K., KNOX, K. W. \& WiCkeN, A. J. (1981). Effect of fructose and other carbohydrates on the surface properties, lipoteichoic acid production, and extracellular proteins of Streptococcus mutans Ingbritt grown in continuous culture. Infection and Immunity 31, 78-87.

Hughes, M., Machardy, S. M., Sheppard, A. J. \& Woods, N. C. (1980). Evidence for an immunological relationshiip between Streptococcus mutans and human cardiac tissue. Infection and Immunity 27, $567-588$.

KARCHER, D., LOWENTHAL, A., THORMAR, H. \& NOPPE, M. (1981). Serological identification of viral antigens after electrophoretic transfer. Journal of Immunological Methods 43, 175-179.

Kessler, S. W. (1981). Use of Protein-A bearing staphylococci for the immunoprecipitation and isolation of antigens from cells. Methods of Enzymo$\log y$ 73, 442-458.

MCGHEe, J. R. \& MichaleK, S. M. (1981). Immunobiology of dental caries: microbial aspects and local immunity. Annual Review of Microbiology 35, 595638.

Norrild, B., BJerrum, O. J. \& VestergaArd, B. F. (1977). Polypeptide analysis of individual immunoprecipitates from crossed immunoelectrophoresis. Analytical Biochemistry 81, 432-441.

O'FARrell, P.H. (1975). High resolution two-dimensional electrophoresis of proteins. Journal of Biological Chemistry 10, 4007-4021.

Peach, S. L. \& Russell, R. R. B. (1982). Antigens of Streptococcus mutans cell walls. In Basic Concepts of Streptococci and Streptococcal Diseases, pp. 114-116. Edited by S. E. Holm \& P. Christensen. Chertsey, Surrey: Reedbooks Ltd.

Rosen, A., Ek, K. \& Aman, P. (1978). Agarose isoelectric focusing of native human immunoglobulin $\mathbf{M}$ and $\alpha_{2}$-macroglobulin. Journal of Immunological Methods 28, 1-11.

Russell, M. W. (1979). Purification and properties of a protein surface antigen of Streptococcus mutans. Microbios 25, 7-18.

Russell, M. W., Bergmeier, L. A., Zanders, E. D. \& LEHNER, T. (1980). Protein antigens of Streptococcus mutans: purification and properties of a double antigen and its protease-resistant component. Infection and Immunity 28, 486-493.

Russell, M. W., Caldwell, J. \& Lehner, T. (1979). Antibody response to Streptococcus mutans antigens during immunisation against dental caries. In Pathogenic Streptococci, pp. 117-218. Edited by M. T. Parker, Chertsey, Surrey: Reedbooks Ltd.

RuSSELl, R. R. B. (1979a). Cell-wall protein antigens of Streptococcus mutans. In Pathogenic Streptococci, pp. 221-222. Edited by M. T. Parker. Chertsey, Surrey: Reedbooks Ltd.
RusSELl, R. R. B. (1979b). Wall-associated protein antigens of Streptococcus mutans. Journal of General Microbiology 114, 109-115.

RusSell, R. R. B. $(1979 c)$. Purification of Streptococcus mutans glucosyltransferase by polyethylene glycol precipitation. FEMS Microbiology Letters 6, 197-199.

RuSSELL, R. R. B. (1979d). Glucan-binding proteins of Streptococcus mutans serotype $c$. Journal of General Microbiology 112, 197-201.

RusSELL, R. R. B. $(1979 e)$. Glycosyltransferases of Streptococcus mutans strain Ingbritt. Microbios 23, 135-146.

RusSELL, R. R. B. (1980). Distribution of cross-reactive antigens A and B in Streptococcus mutans and other oral streptococci. Journal of General Microbiology 118, 383-388.

Russell, R. R. B. (1981). Non-specific binding of Streptococcus mutans glucan-binding proteins and lipoteichoic acid to immunosorbent columns. FEMS Microbiology Letters 11, 279-282.

Russell, R. R. B. \& Beighton, D. (1982). Specificity of natural antibodies reactive with Streptococcus mutans in monkeys. Infection and Immunity 35, 741744.

Russell, R. R. B. \& ColmaN, G. (1981). Immunization of monkeys (Macaca fascicularis) with purified Streptococcus mutans glucosyltransferase. Archives of Oral Biology 26, 23-28.

Russell, R. R. B., Beighton, D. \& Cohen, B. (1982). Immunisation of monkeys (Macaca fascicularis) with antigens purified from Streptococcus mutans. British Dental Journal 152, 81-84.

SteinbuCh, M. \& AUdRAN, R. (1969). The isolation of $\mathrm{IgG}$ from mammalian sera with the aid of caprylic acid. Archives of Biochemistry and Biophysics 134, 279-284.

Swanstrom, R. \& Shank, P. R. (1978). X-ray intensifying screens greatly enhance the detection by autoradiography of the radioactive isotopes ${ }^{32} \mathrm{P}$ and ${ }^{125}$ I. Analytical Biochemistry 86, 184-192.

Towbin, H., Staehelin, T. \& GoRdon, J. (1979). Electrophoretic transfer of proteins from polyacrylamide gels to nitrocellulose sheets: procedure and some applications. Proceedings of the National Academy of Science of the United States of America 76, 4350-4354.

Wenham, D. G., Hennessey, T. D. \& Cole, J. A. (1979). Regulation of glucosyl- and fructosyltransferase synthesis by continuous cultures of Streptococcus mutans. Journal of General Microbiology 114, 117 124.

WRIGLEY, C. W. (1971). Gel electrofocusing. Methods in Enzymology 22, 559-564.

Yokogawa, K., Kawata, S., Takemura, T. \& Yoshimura, Y. (1975). Purification and properties of lytic enzymes from Streptococcus globisporus 1829. Agricultural and Biological Chemistry 39, 1533-1543. 